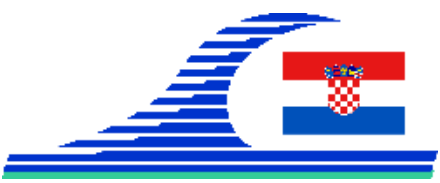

\title{
Volumetric analysis of flow through flushing culverts embedded in breakwaters
}

\author{
Damjan BUJAK $^{1}$, Dalibor CAREVIĆ ${ }^{1}$, Ratko RAMUŠČAK ${ }^{1}$, Ante GAŠPAR ${ }^{1}$
}

1. University of Zagreb, Faculty of Civil Engineering, Fra Andrije Kačića-Miošića 26, Zagreb, Croatia.

dbujak@grad.hr; car@grad.hr; rramuscak@student.grad.hr; agaspar@student.grad.hr

\begin{abstract}
:
Water renewal in harbors and marinas largely depends on the availability of natural generators at a particular location, with tidal oscillations frequently being the most dominant one. In low tidal range areas, it is common to use flushing culverts in order to improve water renewal. Field measurements conducted in ACI marina Opatija point to a significant but brief increase in flow through the flushing culvert due to wind and waves. Considering the whole measuring period, seawater is predominately flowing through the culvert in the direction of the surrounding sea, which may be the result of freshwater sources present in the basin.
\end{abstract}

Keywords: Water renewal, Flushing culvert, Wind, Breakwater, Wind waves, Freshwater sources

\section{Introduction}

Studies have shown that satisfactory water renewal improves water quality in harbors, reduces or eliminates water stagnation and helps maintain wildlife habitats, especially in ecologically sensitive areas (US ENVIRONMENTAL PROTECTION AGENCYUSEPA, 1993; YIN et al., 1998). Natural generators of flow such as tidal oscillations, wind waves, wind forcing and water density differences drive sea water exchange between the harbor basin and the surrounding sea (NECE, 1984; FALCONER \& GUOPING, 1991). Which generators govern the basin flushing depends on the geographical location, although tidal oscillations are usually the most dominant generators. The water renewal rate depends on structural factors such as the plan form geometry of the harbor, entrance dimensions of the harbor; water depth, bed slope, etc. (NECE, 1984; FALCONER \& GUOPING, 1991), which are well investigated. The usage of flushing culverts (pipes or rectangular openings in a breakwater body, diameter/dimension $\mathrm{D} 1 \mathrm{~m}$ ) is suitable in areas with small tidal oscillations (such as the Mediterranean) where the tides alone do not generate satisfactory water exchange (OZHAN \& TORE, 1992). Due to this reason, most significant studies linked to flushing culverts were conducted in countries with small tidal oscillations like Greece and Turkey with an emphasis on wind and wave forcing as the most important 
Mediterranean rocky coasts:

Features, processes, evolution and problems

generators (STAMOU et al., 2004; TSOUKALA \& MOUTZOURIS, 2009; TSOUKALA et al., 2014; BUJAK et al., 2017). In an initiative to further improve flushing culvert design, extensive field measurements have been conducted in ACI marina Opatija to examine the influence of culverts and various natural generators on water renewal (figure 1).

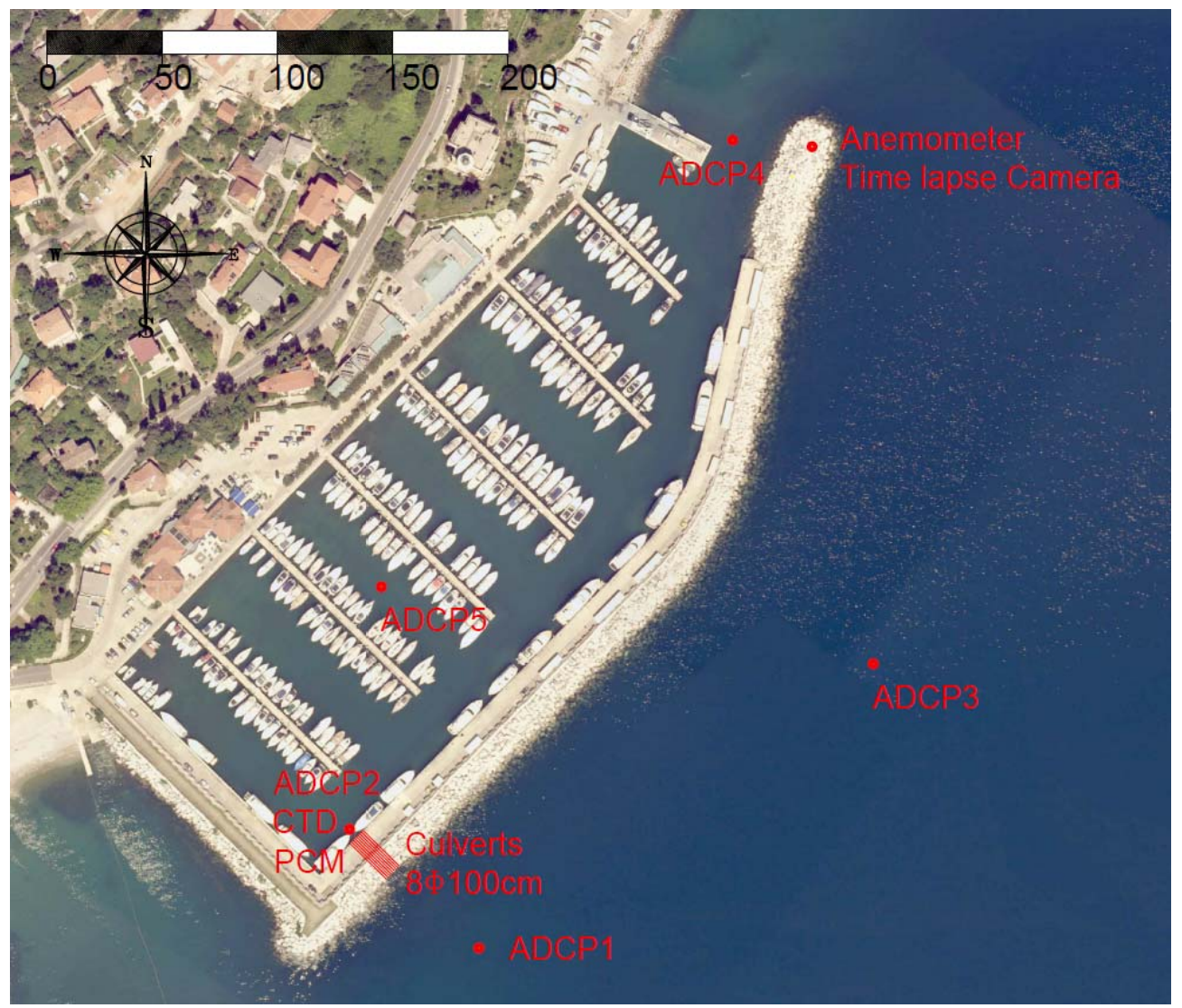

Figure 1. Layout of measuring devices in small marina Opatija.

(ADCP: sea current profiler; CTD: salinity and temperature; PCM: velocity and discharge in the flushing culvert; Anemometer: wind magnitude and direction; Time lapse camera: video observations of the marina area).

\section{Materials and methods}

ACI marina Opatija was chosen as a suitable location because it has eight built-in $1 \mathrm{~m}$ diameter pipe culverts placed in the breakwater opposite of the inlet to the marina. The top of the culvert is vertically placed at mean sea level and the offset distance between each culvert is $0.5 \mathrm{~m}$. The area is known for existing strong freshwater sources. The site also has frequent north-northeast and south-southwest winds. On February 15, 2017, five ADCP devices, one CTD probes, one PCM device, anemometer and camera were positioned in the marina (figure 1). Due to battery constraints, some measuring devices stopped recording after 30 days. The devices were recovered on March 31, 2017. 
Mediterranean rocky coasts:

Features, processes, evolution and problems

\section{Results}

During the measuring period, tidal ranges were regularly at about $0.4 \mathrm{~m}$ and five major wind events have been detected (figure 2). The first three events had winds approaching the marina from south-southwest and the last two from north-northeast with hourly averaged velocities up to $9.5 \mathrm{~m} / \mathrm{s}$. The SSW winds also generated incident waves with a significant wave height up to $1.2 \mathrm{~m}$ (figure 3 ). The first two wind events produced (in conjunction with the generated wind waves) significant seawater flow in the direction of the basin (visible on the cumulative volume graph on figure 2 with a positive slope of the tangent line during said events) through the flushing culvert. The third event did not produce the same result due to freshwater sources (induced by precipitation in the nearby area at the time) in the marina flowing in the opposite direction and generally higher surface elevation, most of the time above the top of the culvert. According to previous studies, the inflow produced by waves is dramatically reduced if the surface elevation is above the top of the culvert (BUJAK et. al., 2017). As the NNE winds were blowing from the direction of the marina inlet, they probably contributed to seawater flow through the culvert primarily in the direction of the surrounding sea. Five noteworthy rain events occurred during the measuring period (with precipitation higher than $10 \mathrm{~mm} /$ day), with the second producing substantial outflow from the marina (visible on the cumulative volume graph on figure 2 with a negative slope of the tangent line during the second rain event). The precipitation measurements, that recorded the amount of rainfall, were conducted at a rain gauge in the city of Rijeka (figure 1). The timing of the rain events presented was modified according to visual observations made by the time lapse camera that monitored the marina. This discrepancy occurred because the city of Rijeka, where the rain gauge was positioned, is located $12 \mathrm{~km}$ northeast from the marina across the bay of Rijeka. The salinity is observed by the CTD probe at the culvert entrance and the scatter set presented corresponds to a water depth of $0.4 \mathrm{~m} \pm 1$ $\mathrm{cm}$ (figure 2). The drops in salinity to almost $27 \mathrm{ppm}$, coincide with the rain events observed in the marina. During a decrease in salinity on the $11^{\text {th }}$ of March there were no rain events observed on the site of the marina or in the city of Rijeka. The area is known for freshwater sources caused by precipitation inland that could percolate quickly through the karst. Therefore, freshwater sources in conjunction with a wind velocity increase (the second peak of the last significant wind event) that accelerated seawater mixing were the most probable cause of the salinity drop. 
Mediterranean rocky coasts:

Features, processes, evolution and problems

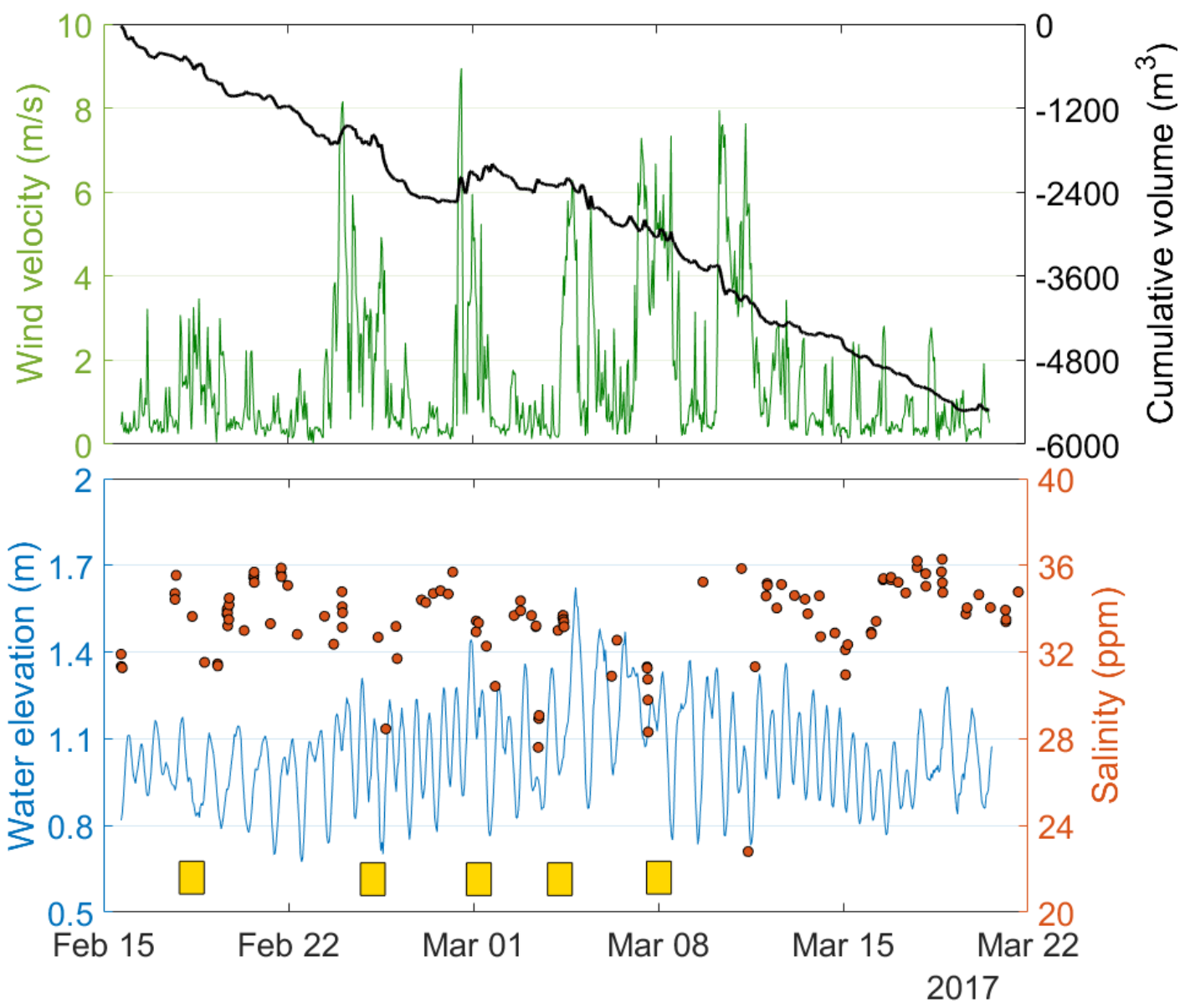

Figure 2. Time series recorded by field devices.

(green: wind velocity measured by the anemometer; black: cumulative volume that passed through the culvert measured by the PCM; blue: surface elevation in time; the bottom of the flushing culvert indicated with $0 \mathrm{~m}$ and the top with $1 \mathrm{~m}$; orange: salinity measurements with the CTD probe at the depth of $0.4 \mathrm{~m}$; gold: events of precipitation detected at the area higher than $10 \mathrm{~mm} /$ day).

During the measuring period, seawater is leaving the marina through the culvert with an average flow rate of $7 \mathrm{~m}^{3} / \mathrm{h}$. Laboratory measurements were conducted to measure the velocities inside flushing culverts when the flow is only forced by irregular incident waves approaching at a perpendicular angle to the breakwater (BUJAK et al., 2017). The following equation relating wave height $(\mathrm{H})$, wave length $(\mathrm{L})$, culvert diameter $(\mathrm{d})$, culvert length $\left(\mathrm{L}_{\mathrm{c}}\right)$, submergence coefficient $(\mathrm{w})$ and velocity inside the culvert $(\mathrm{v})$ was deduced:

$v_{p}=\sqrt{g d} \cdot\left(0.097 \cdot\left(\frac{H \cdot L}{d \cdot L_{C} \cdot w^{4}}\right)^{0.34}-0.11\right)$ 


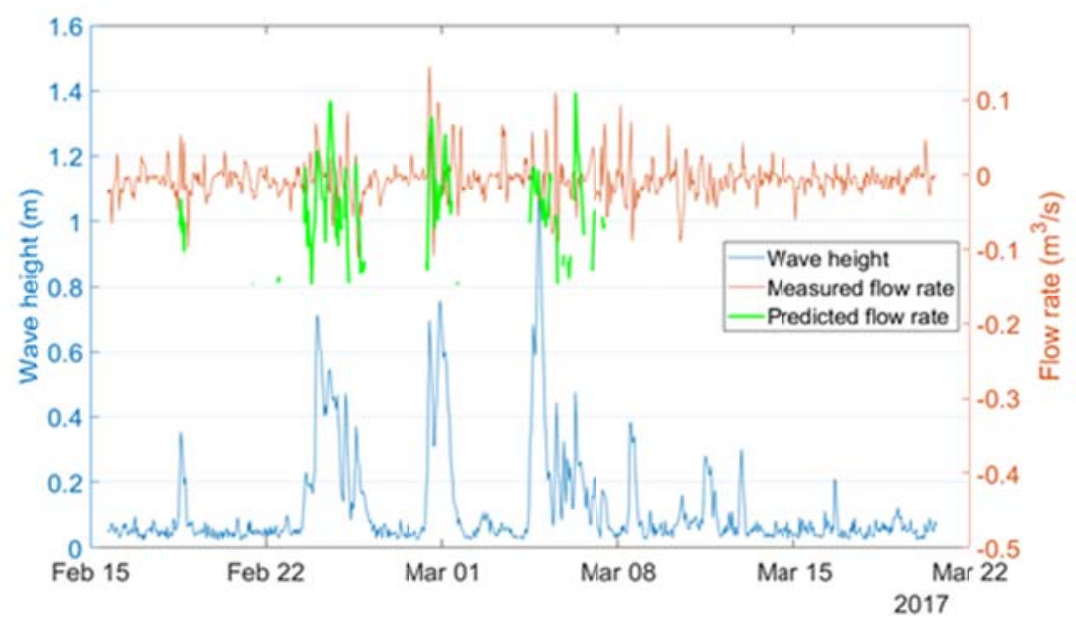

Figure 3. Time series measured by field devices.

(blue: wave height measured by ADCP1; red: flow rate that passes through the culvert measured by the PCM device; green: predicted flow rates by the equation (1).

Utilizing hourly averaged values of measured wave parameters and cullvert geometrical characteristics (wave height, culvert diameter and others), a velocity time series prediction using equation (1) was calculated. Flow rates were calculated under the assumption of a uniform velocity distribution on the cross-sectional area of flow. When hourly averaged measured flow rates through the culvert are compared with the values predicted by equation (1), the values do not completely agree. Although there is agreement in some trends, when comparing field flow rate values with laboratory values the root mean squared error (RMSE) is 0.06 which is not satisfactory, considering the range of the measured values is about $0.2 \mathrm{~m} / \mathrm{s}$. There are several natural generators that could influence the flow rate that are not taken into account in the aforementioned equation. The effects of wind velocity and direction, freshwater sources inside the marina, tidal oscillations, incident angle of waves (equation (1) was formed taking into account only the perpendicular direction of waves), breakwater slope angle and vessel movement. The discrepancy could be expected as equation (1) was developed with measurements in a laboratory environment with waves being the only gienerator of flow. It can be observed that even though waves have a significant impact on flow rates, their influence is not as dominant to disregard other natural generators and their respective effect on the flow rate. Further investigations, using numerical models and fields measurements, are planned in order to resolve the mentioned issues regarding the influence of waves on flow in conjunction with other natural generators.

\section{Conclusions}

In areas where tidal oscillations alone are not satisfactory generators of water renewal, flushing culverts are often used to improve the seawater circulation inside the basin. 
Mediterranean rocky coasts:

Features, processes, evolution and problems

Taking into consideration the whole measuring period, a dominant outflow through the culvert can be observed probably due to widespread freshwater sources inside the marina. Significant drops in salinity could be observed that respond to rainfall, freshwater sources in the marina and wind-induced mixing of the basin. Wind and waves produce significant although brief flows through the culvert. Comparing a laboratory derived equation (considered only the influence of waves) and field measurements, discrepancies were observed. Considering other generators of flow that are present in conjunction with waves (e.g. wind, tides etc.), waves are not the only major producers of flow through culverts.

\section{Acknowledgements}

This work has been fully supported by the Croatian Science Foundation under the project number UIP-2014-09-6774.

\section{References}

BUJAK D., CAREVIĆ D., MOSTEČAK H. (2017). Velocities inside flushing culverts induced by waves. Proc. of the Inst. of Civil Engineers, Maritime Engineering, in press. FALCONER R. A., GUOPING Y. (1991). Effects of depth, bed slope and scaling on tidal currents and exchange in a laboratory model harbor. Proc. of the Inst. of Civil Engineers, Part 2, Vol. 91, (3), pp. 561-576. https://doi.org/10.1680/iicep.1991.15630

NECE B. R. E. (1984). Planform effects on tidal flushing of marinas, Journal of Waterway, Port, Coastal and Ocean Engineering, Vol. 110, (2), pp. 251-269. doi: 10.1061/(ASCE)0733-950X(1984)110:2(251)

OZHAN E., TORE E. (1992). Studies for improving flushing ability of Marmaris marina, Ed. Comp. Mech. Publication, 267 p. https://doi.org/10.1680/mt.16897.0019

STAMOU I., KATSIRIS I. K., MOUTZOURIS C. I., TSOUKALA V. K. (2004). Improvement of marina design technology using hydrodynamic models. Global Nest Journal, Vol. 6, (1), pp. 63-72.

TSOUKALA V. K., KATSARDI V., BELIBASSAKIS K. A. (2014). Wave transformation through flushing culverts operating at seawater level in coastal structures. Ocean Eng., Elsevier, Vol. 89(1), pp. 211-229. doi: 10.1016/j.oceaneng.2014.08.009.

TSOUKALA V.K., MOUTZOURIS C.I. (2009). Wave transmission in harbors through flushing culverts, Ocean Eng., Vol. 36 (6-7), pp. 434-445. doi: 10.1016/j.oceaneng.2009.01.005

USEPA. (1993). Environmental engineering for small boat basins. Engineer Manual 1110-2-1206, U.S. Army Corps of Engineers, Washington, DC 20314-1000.

YIN J., FALCONER R. A., PIPILIS K., STAMOU A. I. (1998). Flow characteristics and flushing processes in marinas and coastal embayments, Proc. of the $1^{\text {st }}$ Int. Conf. on Maritime Engineering and Ports, Genoa, pp. 88-98. 